\title{
Editorial for special issue on advanced materials for energy storage and conversion
}

\author{
Qiao-bao Zhang ${ }^{1)}$, Yong-chang Liu' ${ }^{2}$, and Xiao-bo Ji $i^{3)}$ \\ 1) Department of Materials Science and Engineering, College of Materials, Xiamen University, Fujian 361005, China \\ 2) Beijing Advanced Innovation Center for Materials Genome Engineering, Institute for Advanced Materials and Technology, State Key Laboratory for Advanced \\ Metals and Materials, University of Science and Technology Beijing, Beijing 100083, China \\ 3) State Key Laboratory of Powder Metallurgy, College of Chemistry and Chemical Engineering, Central South University, Changsha 410083, China
}

The ever-increasing environmental problems and energy challenges have called urgent demand for utilizing green, efficient, and sustainable energy, thus promoting the development of new technologies associated with energy storage and conversion systems. Amongst a wealth of energy storage devices, $\mathrm{Li} / \mathrm{Na} / \mathrm{K} / \mathrm{Zn} / \mathrm{Mg}$ ion batteries, metal-air batteries, and lithium-sulfur/all-solid-state batteries together with supercapacitors as advanced power sources have attracted considerable interest due to their conspicuous merits of high energy density, long cycle life, and good rate capability. In the energy conversion systems, solar cells and fuel cells can be considered as mainstream renewable energy resources once their manufacturing cost has decreased to an affordable level. However, the developments of advanced power sources depend critically on advances in materials innovation. Therefore, to promote the practical applications of these promising systems, developing high-performance electrode materials has been taken into the center stage in current research areas from chemistry, physics, and materials science fields.

Here we inspire a special issue focusing on the recent development and achievements in the design, synthesis, structure-engineering, and optimization of electrode materials for application in catalysis, battery, and supercapacitors, aiming to highlight the strategies and fundamental mechanisms for improving the electrochemical behaviors based on both the experimental studies and theoretical simulations.

This special issue includes 18 papers, namely, 15 research papers and 3 review papers on designing advanced electrode materials for applications in catalysis, supercapacitors, and batteries. Majority of papers mainly focused on the research development in realizing the optimization of electrode materials for electrochemical energy storage, which provide a guidance and improve our understanding of high-efficiency materials for commercial applications in various electrochemical energy-related devices

Silicon (Si) anode has been considered as one of the main innovation pathways for improving the energy density of lithium-ion batteries (LIBs) because Si has ten times higher theoretical capacity $\left(3579 \mathrm{mAh} \cdot \mathrm{g}^{-1}\right)$ comparing with those of conventional graphite $\left(372 \mathrm{mAh} \cdot \mathrm{g}^{-1}\right)$. However, it suffers from dramatic volume expansion $(>300 \%)$ and low electronic conductivity. To address these issues, Du et al. [1] reported a new idea of using carbon dots (CDs) modification on $\mathrm{Si}$ ( $\mathrm{Si} / \mathrm{CDs}$ ) to enhance the interaction between the Si particles and binders. The as-prepared $\mathrm{Si} / \mathrm{CD}$ electrodes showed good mechanical structure stability and electrochemical performance $(64 \%$ capacity retention was achieved at $0.2 \mathrm{C}$ for 150 cycles). Qiao et al. [2] designed a chain-like structure composite, in which ZIF-67 derived porous carbon acts as a shell structure to integrally encapsulate Si nanoparticles, and carbon nanotubes (CNTs) play a role in connecting carbon shells. In this composite, the carbon shell can cushion the volume expansion and CNTs can improve overall stability and conductivity. Benefitting from these structural superiorities, the as-fabricated composite electrode revealed superior rate capacity and cycling stability, which in particular achieves a capacity of $732 \mathrm{mAh} \cdot \mathrm{g}^{-1}$ at $2 \mathrm{~A} \cdot \mathrm{g}^{-1}$ and shows a reservation rate of $72.3 \%$ after cycling 100 times at $1 \mathrm{~A} \cdot \mathrm{g}^{-1}$. To prevent the $\mathrm{Si} / \mathrm{C}$ anode from cracking during the cycle, Yang et al. [3] used $\mathrm{SrF}_{2}$ to coat the $\mathrm{Si} / \mathrm{C}$ anode electrode. The $\mathrm{SrF}_{2}$ coating layer is proven to be favorable to form a more stable and mechanically strong solid electrolyte interface (SEI), thus the Si/C electrode exhibited more excellent cycling stability. Moreover, Feng et al. [4] gave a comprehensive review on the research progress of Si-based alloy anode from three different systems, including $\mathrm{Si} / \mathrm{Li}$-active sys- 
tem ( $\mathrm{Si}-\mathrm{Mg}, \mathrm{Si}-\mathrm{Ge}, \mathrm{Si}-\mathrm{Zn}$ ), $\mathrm{Si} / \mathrm{Li}$-inactive system ( $\mathrm{Si}-\mathrm{Fe}$, $\mathrm{Si}-\mathrm{Ni}, \mathrm{Si}-\mathrm{Ti}, \mathrm{Si}-\mathrm{Cu}$ ), and some controversial and original systems ( $\mathrm{Si}-\mathrm{Ti}-\mathrm{Ni}$ system, $\mathrm{Si}-\mathrm{Li}$ alloy, and $\mathrm{Si}$-inactive NM system). Additionally, a three-dimensional $\mathrm{Sb}_{2} \mathrm{~S}_{3}$ anode modified with CNTs interphase was reported by Wang et al. [5], which exhibited good cycling stability with a high capacity retention of $94.7 \%$ after 160 cycles at $0.5 \mathrm{C}$ and a high reversible rate capacity of $760.8 \mathrm{mAh} \cdot \mathrm{g}^{-1}$ at $10 \mathrm{C}$.

All-solid-state Li-ion batteries (ASSLIBs) have been widely studied to achieve LIBs with high safety and high energy density. It is well known that the development of highperformance ASSLIBs relies heavily on advances in solidstate electrolytes (SSEs) innovation. However, the current SSEs still have some disadvantages such as low ionic conductivity, poor interfacial compatibility with solid electrodes. To solve these problems, Wei et al. [6] prepared a novel solid composite electrolyte (SCE) that is consisted of nanostructured MOFs (UiO-66- $\mathrm{NH}_{2}$ ), surface-functionalized metal oxide particles $\left(\mathrm{S}-\mathrm{ZrO}_{2}\right)$, and PVDF-HFP polymer. It was found that the SCE can effectively immobilize anions by strong Lewis acid-based interaction, achieving a high Li-ion transference number and ionic conductivity. Moreover, garnet-structured $\mathrm{Li}_{7} \mathrm{La}_{3} \mathrm{Zr}_{2} \mathrm{O}_{12}$ (LLZO) is highly regarded an SSE with excellent application potential. In order to give an overview of LLZO for ASSLIBs, Zhang et al. [7] summarized recent developments on garnet-structured LLZO including the preparation, element doping, structure, stability, and interfacial improvement of LLZOs and provided comprehensive insights to guide the development of garnet-structured LLZO-type electrolytes. Interfacial issues in ASSLIBs include the electrochemical decomposition reaction at the electrode-electrolyte interface and the low effective contact area between the solid electrolyte and the electrode, and they have currently evoked a plethora of research. Wang et al. [8] provided a systematic summarization on the research activities of solid electrolyte interface treatment based on buffer layer therapy, especially the matching degree between different buffer layers and different interface issues, and what methods may improve buffer layer performance. This review could help to advance future research and development of ASSLIBs.

SSEs also demonstrate a bright application prospect in the commercialization of lithium-sulfur ( $\mathrm{Li}-\mathrm{S}$ ) batteries. $\mathrm{Li}-\mathrm{S}$ battery is identified as one of the most promising energy storage devices in the future because of its high energy density, portability, and cost effectiveness. However, the problems such as the low conductivity of sulfur, shuttle effect of soluble lithium polysulfide in organic electrolyte, and volume expansion of electrodes impede its further developments. To handle these challenges, Duan et al. [9] designed a hollow Ndoped carbon coated $\mathrm{CoO} / \mathrm{SnO}_{2}\left(\mathrm{CoO} / \mathrm{SnO}_{2} @ \mathrm{NC}\right)$ composite to increase the sulfur loading. The nitrogen-doped carbon shell provides good conductivity, the hollow core-shell struc- ture can relieve the volume expansion, $\mathrm{CoO} / \mathrm{SnO}_{2}$ cores can provide strong absorption of polysulfides and reduce the "shuttle effect" during charging and discharging. Therefore, the $\mathrm{CoO} / \mathrm{SnO}_{2} @ \mathrm{NC} / \mathrm{S}$ composite as cathode material for Li-S batteries exhibited excellent lithium-storage performances with an initial discharge capacity of $395.7 \mathrm{mAh} \cdot \mathrm{g}^{-1}$ at $0.2 \mathrm{C}$ and $302.7 \mathrm{mAh} \cdot \mathrm{g}^{-1}$ after 400 cycles. Wu et al. [10] synthesized porous $\mathrm{g}-\mathrm{C}_{3} \mathrm{~N}_{4}$ nanotubes (PCNNTs) as an efficient sulfur host material for high-performance $\mathrm{Li}-\mathrm{S}$ batteries. PCNNTs with a tubular structure could alleviate the volume expansion caused by sulfur and lithium sulfide during charge/discharge cycling. High N contents could greatly enhance the adsorption capability of the carbon nitride for lithium polysulfides (LPSs). These synergistic effects contribute to the excellent cycling stability and rate performance of the PCNNTs/S composite electrode.

Sodium-ion batteries (SIBs)/potassium-ion batteries (PIBs) are considered as promising next-generation energy storage devices. However, a lack of appropriate high-performance anode materials has prevented further improvements. Antimony (Sb) with high theoretical capacity has attracted considerable interest as potential anodes in SIBs and PIBs, but it suffers from huge volume variation during cycling, which poses a critical challenge for stable battery operation. Wang et al. [11] synthesized an ultrafine $\mathrm{Cu}_{2} \mathrm{Sb}$ nanoalloy confined in three-dimensional porous carbon material with freeze-drying followed by a high temperature sintering process. The 3D porous structure with large surface area offers sufficient interspace to accommodate the volume expansion of $\mathrm{Sb}$ and suppress nanoparticle aggregation. The inactive $\mathrm{Cu}$ with high conductivity further improved the structure stability. As a result, the composite shows superior cycling durability (the capacity can be maintained at $328.3 \mathrm{mAh} \cdot \mathrm{g}^{-1}$ after 100 cycles for SIBs and $260 \mathrm{mAh} \cdot \mathrm{g}^{-1}$ for PIBs). Moreover, organic electrode materials with high theoretical specific capacity as anodes for SIBs face many challenges in practical application, such as high discharge plateau and high solubility in organic electrolytes. Chen et al. [12] successfully synthesized tetrahydroxy benzoquinone tetrasodium salt $\left(\mathrm{Na}_{4} \mathrm{C}_{6} \mathrm{O}_{6}\right)$ as an anode for SIBs. The as-prepared $\mathrm{Na}_{4} \mathrm{C}_{6} \mathrm{O}_{6}$ electrode with four - $\mathrm{ONa}$ electron donating groups added on structure of BQ (p-benzoquinone) reduces the discharge plateau from $\sim 2.7$ to $\sim 1.2 \mathrm{~V}$ greatly with the decrease value of over $1.4 \mathrm{~V}$, which can make BQ change from cathode to anode material for SIBs.

Battery technologies beyond LIBs, SIBs, and PIBs, such as zinc-ion batteries (ZIBs) and Mg-air batteries, have also been widely studied due to their high safety or high specific energy. Particularly, developing high-performance electrodes plays a critical role in the practical application of these promising battery technologies in the future. For example, Qin et al. [13] fabricated $\mathrm{Ba}_{0.23} \mathrm{~V}_{2} \mathrm{O}_{5} \cdot 1.1 \mathrm{H}_{2} \mathrm{O}(\mathrm{BaVO})$ nanobelts as cathode materials of ZIBs. Benefiting from the in- 
creased interlayer distance of $1.31 \mathrm{~nm}$ by $\mathrm{Ba}^{2+}$ and $\mathrm{H}_{2} \mathrm{O}$ preintercalation, the obtained $\mathrm{BaVO}$ nanobelts showed an excellent initial discharge capacity of $378 \mathrm{mAh} \cdot \mathrm{g}^{-1}$ at $0.1 \mathrm{~A} \cdot \mathrm{g}^{-1}$, a great rate performance $\left(172 \mathrm{mAh} \cdot \mathrm{g}^{-1}\right.$ at $\left.5 \mathrm{~A} \cdot \mathrm{g}^{-1}\right)$, and a superior capacity retention $\left(93 \%\right.$ after 2000 cycles at $\left.5 \mathrm{~A} \cdot \mathrm{g}^{-1}\right)$. Boroujeny et al. [14] investigated the microstructural properties and electrochemical performance of $\mathrm{Zn}$ sacrificial anodes during strain-induced melt activation. The electrochemical test results for the $50 \%$ cold-worked sample confirmed that the corrosion current density declined by $90 \%$ and the anode efficiency slightly decreased relative to that of the raw sample. Yang et al. [15] studied the discharge property of $\mathrm{Mg}$-air batteries employing $\mathrm{Mg}-\mathrm{Sn}-\mathrm{Y}$ alloys with different Sn contents $(\leq 0.7 \mathrm{wt} \%)$ as anode materials. The $\mathrm{Mg}-0.7 \mathrm{Sn}-1.4 \mathrm{Y}$ alloy possessed a high steady discharge voltage of $1.5225 \mathrm{~V}$ and a high anodic efficiency of $46.6 \%$ at $2.5 \mathrm{~mA} \cdot \mathrm{cm}^{-2}$. These good properties were related to its microstructure: small grain size of $3.8 \mu \mathrm{m}$, uniform distribution of small second phase particles of $0.6 \mu \mathrm{m}$, and a high content (vol\%) of $(11 \overline{20}) /(1010)$ orientated grains.

In addition, there are several works regarding the catalysis, graphite oxide, and supercapacitors in this special issue, which exhibit their respective advantages in energy storage and conversion applications. For example, Liu et al. [16] synthesized atom-precise silver nanoclusters (NCs) in high purity by a kinetically controlled strategy. The silver NCs were supported on the active carbon (AC) to form the $\mathrm{Ag} \mathrm{NCs/AC,}$ which displayed excellent activity for the catalytic reduction of 4-nitrophenol with the kinetic reaction rate constant $k$ of $0.21 \mathrm{~min}^{-1}$. Besides, the catalytic activity of $\mathrm{Ag} \mathrm{NCs} / \mathrm{AC}$ kept almost constant after six times of recycle, suggesting its good stability. Atta et al. [17] successfully prepared the $\gamma$-ray-reduced graphene oxide samples (GRGOs) by using high absorbed doses of $\gamma$-rays. They found that radiation reduction is an ideal method for RGO preparation, especially when the resulting RGO is applied in devices such as supercapacitors and thermal resistors. Zhang et al. [18] fabricated the $\mathrm{MnO}_{2}$ /biomass carbon nanocomposite by a facile hydrothermal reaction. The biomass carbon not only offered the high conductivity and good structural stability but also relieved the large volume expansion during the charge/discharge process. Therefore, the obtained $\mathrm{MnO}_{2}$ /biomass carbon nanocomposite electrode exhibited a high specific capacitance $\left(238 \mathrm{~F} \cdot \mathrm{g}^{-1}\right.$ at $\left.0.5 \mathrm{~A} \cdot \mathrm{g}^{-1}\right)$ and prolonged cycling stability ( $93 \%$ remaining after 2000 cycles).

The special issue summarized some of the latest advancement in the design, synthesis, structure-engineering, and optimization of electrode materials for application in catalysis, battery, and supercapacitors, which will provide helps for readers to explore new research directions in the interdisciplinary fields of metallurgy, materials, environment, energy, and so on. So, we are appreciated to all authors for their innovative works and all reviewers for their helpful comments.
We sincerely thank the Editorial Team of International Journal of Minerals, Metallurgy and Materials for their hard work to get the publication of special issue.

\section{References}

[1] Q.K. Du, Q.X.Wu, H.X. Wang, X.J. Meng, Z.K. Ji, S. Zhao, W.W. Zhu, C. Liu, M. Ling, and C.D. Liang, Carbon dot-modified silicon nanoparticles for lithium ion batteries, Int. J. Miner. Metall. Mater., 28(2021), No. 10, p. 1603.

[2] Y.J. Qiao, H. Zhang, Y.X. Hu, W.P. Li, W.J. Liu, H.M. Shang, M.Z. Qu, G.C. Peng, and Z.W. Xie, A chain-like compound of $\mathrm{Si} @ \mathrm{CNTs}$ nanostructure and MOF-derived porous carbon as anode for Li-ion batteries, Int. J. Miner. Metall. Mater., 28(2021), No. 10, p. 1611

[3] J. Yang, Y.H. Lin, B.S. Guo, M.S. Wang, J.C. Chen, Z.Y. Ma, Y. Huang, and X. Li, Enhanced electrochemical performance of $\mathrm{Si} / \mathrm{C}$ electrode through surface modification using $\mathrm{SrF}_{2}$ particle, Int. J. Miner. Metall. Mater., 28(2021), No. 10, p. 1621.

[4] Z.Y. Feng, W.J. Peng, Z.X. Wang, H.J. Guo, X.H. Li, G.C. Yan, and J.X. Wang, Review on silicon-based alloys for lithium ion battery anode, Int. J. Miner. Metall. Mater., 28(2021), No. 10, p. 1549 .

[5] Q. Wang, Y.Y. Du, Y.Q. Lai, F.Y. Liu, L.X. Jiang, and M. Jia, Three-dimensional antimony sulfide anode with carbon nanotube interphase modified for lithium-ion batteries, Int. $J$. Miner. Metall. Mater., 28(2021), No. 10, p. 1629.

[6] T. Wei, Z.H. Zhang, Q. Zhang, J.H. Lu, Q.M. Xiong, F.Y. Wang, X.P. Zhou, W.J. Zhao, and X.Y. Qiu, Anion-immobilized solid composite electrolytes based on metal-organic frameworks and superacid $\mathrm{ZrO}_{2}$ fillers for high-performance all solidstate lithium metal batteries, Int. J. Miner. Metall. Mater., 28(2021), No. 10, p. 1636.

[7] Z.H. Zhang, T. Wei, J.H. Lu, Q.M. Xiong, Y.H. Ji, Z.Y. Zhu, and L.T. Zhang, Practical development and challenges of garnet-structured $\mathrm{Li}_{7} \mathrm{La}_{3} \mathrm{Zr}_{2} \mathrm{O}_{12}$ electrolytes for all-solid-state lithium-ion batteries: A review, Int. J. Miner. Metall. Mater., 28(2021), No. 10, p. 1565.

[8] L.Y. Wang, L.F. Wang, R. Wang, R. Xu, C. Zhan, W. Yang, and G.C. Liu, Solid electrolyte-electrode interface based on buffer therapy in solid-state lithium batteries, Int. J. Miner. Metall. Mater., 28(2021), No. 10, p. 1584.

[9] M.T. Duan, M.R. Wu, K. Xue, Z.X. Bian, J. Shi, X.M. Guo, F. Cao, J.H. Zhang, Q.H. Kong, and F. Zhang, Preparation of $\mathrm{CoO} / \mathrm{SnO}_{2} @ \mathrm{NC} / \mathrm{S}$ composite as high-stability cathode material for lithium-sulfur batteries, Int. J. Miner. Metall. Mater., 28(2021), No. 10, p. 1647.

[10] M.R. Wu, M.Y. Gao, S.Y. Zhang, R. Yang, Y.M. Chen, S.Q. Sun, J.F. Xie, X.M. Guo, F. Cao, and J.H. Zhang, High-performance lithium-sulfur battery based on porous N-rich g- $\mathrm{C}_{3} \mathrm{~N}_{4}$ nanotubes via a self-template method, Int. J. Miner. Metall. Mater., 28(2021), No. 10, p. 1656.

[11] D. Wang, Q. Ma, K.H. Tian, C.Q. Duan, Z.Y. Wang, and Y.G. Liu, Ultrafine nano-scale $\mathrm{Cu}_{2} \mathrm{Sb}$ alloy confined in three-dimension porous carbon as anode for sodium-ion and potassium-ion batteries, Int. J. Miner. Metall. Mater., 28(2021), No. 10, p. 1666.

[12] F.H. Chen, Y.W. Wu, H.H. Zhang, Z.T. Long, X.X. Lin, M.Z. Chen, Q. Chen, Y.F. Luo, S.L. Chou, and R.H. Zeng, The modulation of discharge plateau of benzoquinone for sodium-ion batteries, Int. J. Miner. Metall. Mater., 28(2021), No. 10, p. 1675.

[13] X.H. Qin, Y.H. Du, P.C. Zhang, X.Y. Wang, Q.Q. Lu, A.K. 
Yang, and J.C. Sun, Layered barium vanadate nanobelts for high-performance aqueous zinc-ion batteries, Int. J. Miner. Metall. Mater., 28(2021), No. 10, p. 1684.

[14] B.S. Boroujeny, P.R. Goojani, and E. Akbari, Effects of straininduced melt activation treatment on the microstructure and properties of $\mathrm{Zn}$ sacrificial anodes, Int. J. Miner. Metall. Mater., 28(2021), No. 10, p. 1693.

[15] H.B. Yang, L. Wu, B. Jiang, B. Lei, M. Yuan, H.M. Xie, A. Atrens, J.F. Song, G.S. Huang, and F.S. Pan, Discharge properties of $\mathrm{Mg}-\mathrm{Sn}-\mathrm{Y}$ alloys as anodes for $\mathrm{Mg}$-air batteries, Int. J. Miner. Metall. Mater., 28(2021), No. 10, p. 1705.

[16] X.H. Liu, F.H. Wang, C.Y. Shao, G.F. Du, and B.Q. Yao, Kinetically controlled synthesis of atomically precise silver nanoclusters for catalytic reduction of 4-nitrophenol, Int. J. Miner. Metall. Mater., 28(2021), No. 10, p. 1716.

[17] M.M. Atta, H.A. Ashry, G.M. Nasr, and H.A. Abd El-Rehim, Electrical, thermal and electrochemical properties of $\gamma$-ray-reduced graphene oxide, Int. J. Miner. Metall. Mater., 28(2021), No. 10, p. 1726.

[18] P. Zhang, Y.H. Wu, H.R. Sun, J.Q. Zhao, Z.M. Cheng, and X.H. Kang, $\mathrm{MnO}_{2} /$ carbon nanocomposite based on silkworm excrement for high-performance supercapacitors, Int. J. Miner. Metall. Mater., 28(2021), No. 10, p. 1735.

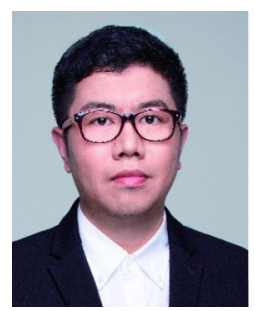

Qiao-bao Zhang is currently an associate professor in the Department of Materials Science and Engineering, College of Materials, at Xiamen University. He obtained his Ph.D. degree from the City University of Hong Kong in 2016. He joined Prof. Meilin Liu's group as a visiting Ph.D. student at the Georgia Institute of Technology in 2015. Then he joined Xiamen University in 2016. His current research focuses on the fundamental issues relevant to energy storage systems including $\mathrm{Li} / \mathrm{Na} / \mathrm{K}$ ion batteries, especially on the key electrode materials, interfacial properties and in situ techniques. Till now, he has published more than 110 papers, nineteen of which are highly cited, which attracted more than 6800 citations with an h-index of 44 .

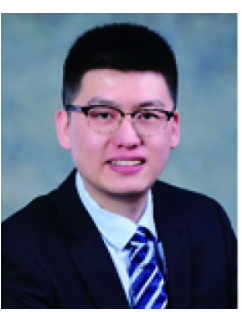

Yong-chang Liu is a Professor at the University of Science and Technology Beijing. He received his BS degree from Beijing Jiaotong University in 2011, and Ph.D. degree from Nankai University in 2016 (Supervisor: Prof. Jun Chen). His research interest focuses on designing high-performance electrode materials for rechargeable batteries (especially for sodium-ion batteries and aqueous zinc-ion batteries), and understanding the in-depth energy storage mechanisms. He has co-authored over 90 relevant peer-reviewed publications with an h-index of 42 .

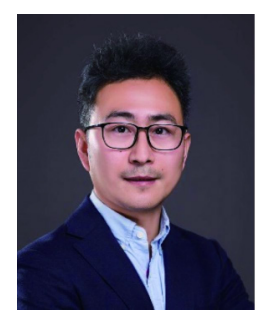

Xiao-bo Ji is a Professor at Central South University, specializing in the research \& development of battery materials and their systems. He has published $280 \mathrm{SCI}$ indexed papers, and he was the winner of highly cited researcher from Clarivate. He proposed a series of novel solutions to improve electrochemical performances of lithium ion batteries and sodium ion batteries, including microstructure design and interface control. 